\title{
English-for-Science-and-Technology Teaching Materials: Phase One Evaluation
}

\author{
Hui-Chuan Liao (Corresponding author) \\ National Kaohsiung University of Applied Sciences \\ 415 Chien-Kung Road, Kaohsiung 80778, Taiwan \\ E-mail: hliao@kuas.edu.tw \\ Yeh-uh Hsueh Chen \\ Chienkuo Technology University \\ 1 Chieshou N. Rd, Changhua City 50094, Taiwan \\ E-mail: yuhc@ctu.edu.tw
}

Received: February 11, 2012

Accepted: March 8, 2012

Published: June 1, 2012

doi:10.5539/elt.v5n6p89

URL: http://dx.doi.org/10.5539/elt.v5n6p89

\begin{abstract}
The importance of English for the workplace, in addition to that of general English proficiency, is receiving increasing attention from educators and policy makers in the field of teaching English as a foreign language. In order to prepare college students for their professional development, appropriate English-for-specific-purposes (ESP) materials, including those for engineering majors, are needed for college courses. This study evaluated teaching materials on English for Science and Technology (EST), in hope of making contributions to the growth of EST materials that meet the educational needs of students in Taiwan. The EST materials were designed for college engineering majors. In the present study, it was used with two engineering junior classes in Taiwan for three weeks. After the trial teaching period, a questionnaire and a focus group interview were administered to collect learner perception on the EST materials. While the overall results of the questionnaire have indicated a positive attitude toward the materials, a careful examination of the statistics and further exploration of the interview data have revealed certain areas of the materials to be improved. Suggestions to the revision of the materials are provided at the end of the paper.
\end{abstract}

Keywords: English for engineers, English for science and technology, English for specific purposes, Material evaluation, Second language teaching, Textbook evaluation

\section{Introduction}

In order to help its citizens meet the challenges of globalization, the Taiwanese government has enacted the Challenge 2008 National Development Plan, with one emphasis of which to boost foreign language mastery, in particular English competence (Council for Economic Planning and Development [CEPD], 2005; Government Information Office [GIO], 2004). Since Taiwan joined the World Trade Organization (WTO) in 2002, the industries in the country have been devoted to upgrading operations to be competitive in the global markets, and thus are in great need of more professional workforce. Enhancing the citizens' English abilities, therefore, has become one of the top priorities set by the Ministry of Education (MOE) (Huang, 2003; Ministry of Education, 2011). Among many endeavors to meet the demands of the globalizing society and industrial sectors and to bring technological and vocational education to new heights, the MOE prescribed improving technological students' foreign language competence, especially that of English, as one of the major educational aims of technological and vocational education. In addition, becoming well-equipped with work skills upon the entrance of the job market is a chief objective of technological institution graduates; English for the workplace is hence a must in such students' foreign language learning (Yu, 2006). Yu argues for the need to develop not only English-for-specific-purposes (ESP) materials in general terms but also learner-centered ESP materials that suits learners of different career focuses. Yu lists examples such as English for car mechanics, English for nurses, and English for medical practitioners. A survey study conducted by Liao, Chen, and Lee (2009) and an evaluation study by Liao and Chang (2011) have further found out that technical college engineering students in Taiwan are presently experiencing a lack of appropriate 
English-for-science-and-technology (EST) textbooks.

In Taiwan, students in vocational high schools are offered only two hours of English lesson per week while regular high school students five to seven hours. Consequently, it has become a great concern of tertiary English teachers that most students in technical institutions do not enter college with a satisfactory level of English competence and that their English proficiency is generally far below that of regular college students (Chen, 2007; Lin, 1997; Yu, 2006).

To most technical college students, English for general purposes (EGP) is a difficult subject to deal with, not to mention English for Science and Technology (EST). How to improve students' EGP and EST competences at the same time has become an essential challenge for English instructors in technical institutions. Effective language instruction takes various factors into account, such as the teacher, the learner, the materials and the context (Richards, 2005). In the case of improving EGP and EST proficiencies of technical college students in Taiwan, suitable instructional materials appear to be increasingly critical.

Such an EST textbook for engineering majors at the basic English level has been recently developed by a collaborative research team. Before the textbook officially launched into classroom use, a test with it in real-life teaching context to detect needed revisions would warrant its appropriateness and practicality. The task of this study was to conduct phase one evaluation of the tentative textbook through a trial teaching, followed with a questionnaire and a focus group interview to collect suggestions for revisions.

\section{Method}

\subsection{Materials}

The textbook included eight chapters on such topics as invention and technology, the Internet, spam, artificial intelligence, the integrated circuit, nanotechnology, robots, and telecommunications. Out of the eight chapters, the one on nanotechnology was selected as materials for the trial teaching, based on its relevance to the subject's field of study. The chapter included nine sections: starting out, conversation, pre-reading, reading, comprehension, cloze, grammar focus, grammar exercise, and discussion. See the Appendix for an excerpt of the materials on the pre-reading and reading sections. Following Dubin and Olshtain's (2000) advice, the researchers prepared a lesson plan with concrete unit objectives and instructional steps to ensure the trial teaching would proceed in the same manner in both subject classes, although taught by different instructors. As the tentative textbook was mainly designed for low-level English language learners, interactive activities and educational games were employed to foster learning in the classroom (Woodward, 2006).

\subsection{Procedure}

A three-week trial teaching was carried out with two classes at a technical university in central Taiwan. A total of 67 students majoring in electrical engineering (EE) took part in the lessons and received firsthand experience with the teaching materials. All the students were juniors. The subjects were considered representative (Fraenkel \& Wallen, 2006) because they had taken English for Technology in the previous semester. It was expected that the subjects' former experience with the English for Technology course might inspire them to provide cogent feedback and suggestions concerning the materials. In the previous semester the average score of students from class $\mathrm{A}$ in a campus-wide English Proficiency Test was 51.6, and that of class B students was 42.3, while the average score of EE students was 45.5. The test scores suggested the students as learners with basic English proficiency.

The trial teaching was carried out in the students' home rooms for two hours per week during the three-week period. The settings were intentionally selected in order for the familiar environment to offer the students ease of mind.

\subsection{Data Collection}

To examine whether the teaching materials are appropriate for the target learners, data were collected via two channels: questionnaire and focus group interview. The questionnaire contained two parts with a total of 12 questions. The first part, Questions 1 through 7, focused on student perceptions of how well the book chapter could improve their basic general English competence, and the second part, Questions 8 through 12, on how well it could improve their EST competence. To ensure that the subjects have a shared reference point when they responded to each item, items of the questionnaire were measured on a five-point Likert scale with the first and the fifth points anchored as "strongly disagree" and "strongly agree." Table 1 shows the questions in the questionnaire.

To further explore the subjects' perceptions on the teaching materials, a focus group interview with four students was conducted after the trial teaching. The four students, all male, were from the same class. Two of the students were at basic English proficiency level and the other two intermediate. 


\section{Results and Discussion}

This section discusses results that have been obtained from two channels of data collection, namely questionnaire and focus group interview. They will be discussed in the following two parts.

\subsection{The Questionnaire}

A total of 67 subjects responded to the questionnaire. They were all electrical engineering majors from two intact classes. Among the subjects, 37 were from class A and 30 from class B. They were dominantly male. Only three subjects were females from class A. Table 2 shows the results of the questionnaire. The reliability was high at .93 .

While the results of the questionnaire indicate there is still room for material improvement, they also show that students' perceptions on the teaching materials were generally positive. Overall, the students considered that the teaching materials would be able to enhance their general English vocabulary $(\mathrm{M}=4.03, \mathrm{SD}=.72)$. They also deemed the materials able to enhance their English grammar skills $(\mathrm{M}=3.93, \mathrm{SD}=.72)$. Additionally, they believed the materials able to increase their general English reading skills $(\mathrm{M}=4.12, \mathrm{SD}=.75)$. Nevertheless, while the students also considered that the materials able to help enhance their general English conversational skills $(\mathrm{M}=3.67$, $\mathrm{SD}=.89$ ), the decreased value of the mean score indicates only a slightly-agree perception. In sum, regarding the development of general English skills, the materials appear to be able to facilitate receptive English skills such as comprehension of vocabulary, grammar, and reading. On the other hand, even though students' perception was slightly positive concerning the helpfulness of the materials on conversational ability development, the reserved attitude could be observed from the statistics $(\mathrm{M}=3.67, \mathrm{SD}=.89)$, which also points out the facilitation of conversational skills as an area that could and should be further strengthened.

In a similar vein, students' perceptions on how well the teaching materials could facilitate their EST skills were generally positive $(\mathrm{M}=4.00, \mathrm{SD}=.72)$. The students found the teaching materials able to enhance their EST vocabulary $(\mathrm{M}=4.10, \mathrm{SD}=.68)$. They further considered the teaching materials able to enhance their EST reading skills $(\mathrm{M}=4.09, \mathrm{SD}=.73)$. On the other hand, a slightly-agree perception $(\mathrm{M}=3.73, \mathrm{SD}=.90)$ shows that the teaching materials should be enhanced in order to effectively facilitate learners' conversational skills in the EST area.

\subsection{The Interview}

Most feedback from the student focus group interview echoed the responses from the questionnaire, yet some stood out distinctively. One basic-level student recommended that at the end of the discussion section, hints be provided to facilitate question discussion. The student also suggested that English songs or jokes be added at the end of the textbook in order to make learning more appealing. Another student suggested the inclusion of comics to boost learner interest. The feedback indicates the importance of scaffolding to support learning and the use of interesting contents to heighten motivation. Other suggestions will be highlighted in the following section.

\section{Conclusion and Suggestions}

The present study provided phase one evaluation of a recently developed textbook so that the textbook could be revised and better meet needs of the target population in both general English and EST skill development. The results of the study have indicated that the teaching materials have basically met the needs of the target learners, who were engineering students mostly with basic level of English proficiency. Synthesizing information from the questionnaire and the focus group interview, the researchers suggest the following areas be focused for revisions of the tentative textbook: learner proficiency level, scaffolding, attractiveness of the materials, relevancy to the major area, and spiral learning.

\subsection{Learner Proficiency Level}

Due to the target students' basic level of English proficiency, it is recommended that articles and conversations be shortened in order to ease learning anxiety and make learning manageable.

\subsection{Scaffolding}

Support should be rendered wherever possible. For example, hints should be provided to help facilitate discussions; example sentences should be added in order for learners to fully understand the usage of new words. Additionally, a glossary, flash cards, and pronunciation prompts would be helpful.

\subsection{Attractiveness of the Materials}

No matter how good the contents are, they have to appeal to the learners to boost learning motivation. A section incorporating useful expressions can be added; articles can deal with more current topics that students find important, and conversation sections could be brought to light with interesting titles. 


\subsection{Relevancy to the Major Areas}

Stronger relevancy brings higher motivation. Therefore, in the beginning of the unit there could be a brief section discussing how the pertaining chapter relates to the readers' future career development. Moreover, more technical terms and phrases related to learners' major areas are desired.

\subsection{Spiral Learning}

New vocabulary items should be introduced in context and then repeatedly cycled in the subsequent sections or units to facilitate learning.

In sum, the EST materials under trial and evaluation facilitate learning in both general English and EST. Further efforts on revisions based on the findings and recommendations of the present study could enhance the quality and effectiveness of the materials. Moreover, in this phase-one evaluative study, the researchers have focused on the students' perceptions of the teaching materials, it is recommended that evaluation factors such as teachers' perceptions and textbook analysis be included in future studies.

\section{References}

Chen, Y.-U. H. (2007). Exploring the assessment aspect of differentiated instruction: College EFL learners' perspectives on tiered performance tasks (Doctoral dissertation, University of New Orleans, 2007). Dissertation Abstracts International, 67(07), 2498A.

Council for Economic Planning and Development. (2005). The challenge 2008 national development plan. Retrieved August 4, 2011, from CEPD Web site: $\mathrm{http}: / / w w w . c e p d . g o v . t w / d n . a s p x ? u i d=917$

Dubin, F., \& Olshtain, E. (2000). Course design. New York: Cambridge University Press.

Fraenkel, J. R., \& Wallen, N. E. (2006). How to design and evaluate research in education (6th ed.). New York: McGraw-Hill.

Government Information Office. (2004). Taiwan yearbook 2004. Retrieved October 15, 2005, from GIO Web site: http://www.gio.gov.tw/taiwan-website/5-gp/yearbook

Huang, J.-T. (2003). Envisioning the 21st century education from the perspectives of international education. National Policy Quarterly, 2(3), 1-26.

Liao, H.-C., \& Chang, H.-Y. (2011). ESP materials for Technical University engineering students: A suitability study. In Y.-J. Chen, S.-J. Huang, L.-N. Hsu, \& T.-C. Lu (Eds.), Studies in teaching English for professional communications (pp. 52-74). Taipei, Taiwan: Crane.

Liao, H.-C., Chen, Y.-U. H., Lee, M.-L. (2009). An ESP needs analysis on college engineering students. In 2009 Conference proceedings of the Hawaii International Conference on Education (pp. 1313-1323). Honolulu, HI, U.S.A.: Hawaii International Conference on Education.

Lin, M.-S. (1997). A comparative study of English teaching in general education and technical education systems in the Republic of China: High schools and junior colleges. (National Science Council Report No. NSC85-2411-H011-001). Taipei, Taiwan: National Science Council.

Ministry of Education. (2011). The current educational situation in Taiwan: Technological and vocational education. Retrieved August 5, 2011 from MOE Web site: http://www.edu.tw/secretary/content.aspx?site_content_sn=21136

Richards, J. C. (2005). The role of textbooks in a language program. Cambridge: Cambridge University Press.

Woodward, T. (2006). Planning lessons and courses. New York: Cambridge University Press.

Yu, G. K. (2006). ESP and English education at technical institutions. Technological and Vocational Newsletter, 174. Retrieved August 5, 2011, form the Ministry of Education Web site: http://120.96.85.9/News/2006111006.asp?c=0200\&vers $=174$ 
Table 1. Question Items in the Questionnaire

\begin{tabular}{|l|l|}
\hline \multicolumn{2}{|l|}{ Part I. Competence in English for General Purposes } \\
\hline 1. & On the whole, the teaching material is able to help me improve my general English skills. \\
\hline 2. & The teaching material is able to enhance my English vocabulary. \\
\hline 3. & The teaching material is able to enhance my English grammar skills. \\
\hline 4. & The teaching material is able to enhance my English reading skills. \\
\hline 5. & The teaching material is able to enhance my English conversational skills. \\
\hline 6. & $\begin{array}{l}\text { The exercises of various formats are able to help me acquire a better understanding of the } \\
\text { chapter content. }\end{array}$ \\
\hline 7. & $\begin{array}{l}\text { The teaching material is appropriate for the use of learners with basic level of English } \\
\text { Pkills. }\end{array}$ \\
\hline 8. & On the whole, the teaching material is able to help me improve my EST skills. \\
\hline 9. & The teaching material is able to enhance my EST vocabulary. \\
\hline 10. & The teaching material is able to enhance my EST reading skills. \\
\hline 11. & The teaching material is able to enhance my EST conversational skills. \\
\hline 12. & The exercises of various formats are able to help me improve my EST skills. \\
\hline
\end{tabular}

Table 2. Results of the Questionnaire

\begin{tabular}{|c|c|c|c|c|}
\hline Item No. & Mean & SD & Minimum & Maximum \\
\hline \multicolumn{5}{|c|}{ Part I. Competence in English for General Purposes } \\
\hline 1 & 3.97 & .72 & 2.00 & 5.00 \\
\hline 2 & 4.03 & .72 & 3.00 & 5.00 \\
\hline 3 & 3.93 & .72 & 3.00 & 5.00 \\
\hline 4 & 4.12 & .75 & 2.00 & 5.00 \\
\hline 5 & 3.67 & .89 & 1.00 & 5.00 \\
\hline 6 & 3.82 & .76 & 2.00 & 5.00 \\
\hline 7 & 3.84 & .90 & 2.00 & 5.00 \\
\hline Part I Average & 3.91 & .61 & 2.71 & 5.00 \\
\hline \multicolumn{2}{|c|}{ Part II. Competence in English for Science and Technology (EST) } \\
\hline 8 & 4.00 & .72 & 2.00 & 5.00 \\
\hline 9 & 4.10 & .68 & 2.00 & 5.00 \\
\hline 10 & 4.09 & .73 & 2.00 & 5.00 \\
\hline 11 & 3.73 & .90 & 1.00 & 5.00 \\
\hline 12 & 3.93 & .78 & 2.00 & 5.00 \\
\hline Part II Average & 3.97 & \multicolumn{6}{|c|}{2.00} & 5.00 \\
\hline
\end{tabular}

\section{Appendix: Excerpt of the Pre-Reading and Reading Section}

\section{3-3 Pre-Reading}

Before you read the following article, mark in the left column whether you think the statement is true $(\circ)$ or false (X). After you read the article, mark in the right column whether the statement is true or false, and then compare your two answers. 


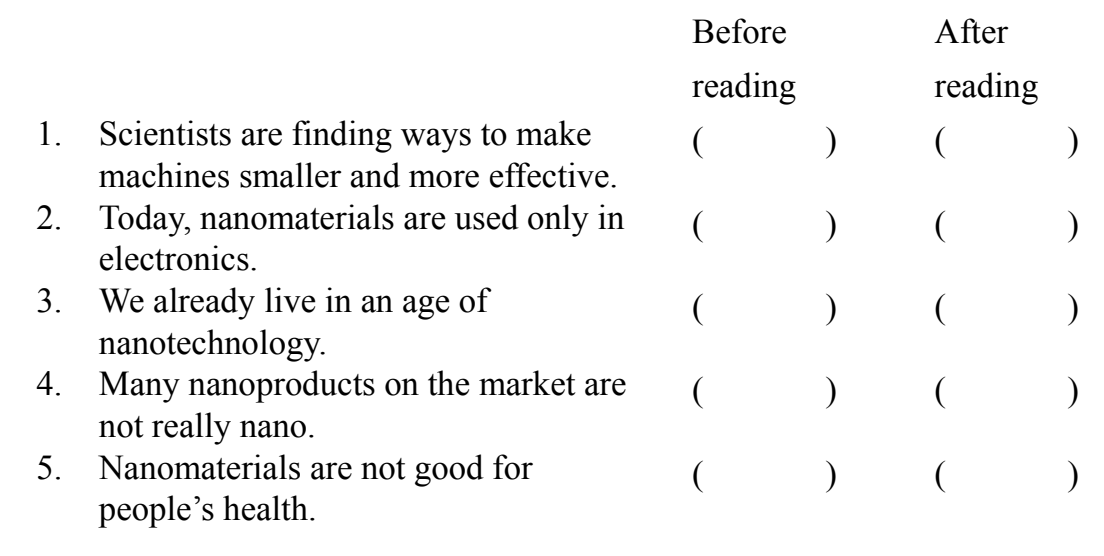

\section{3-4 Reading}

Read the article carefully to check the answers.

\section{Nanotechnology - What Will It Bring Us?}

Most of us have heard about nanotechnology or nanoproducts, and many tend to regard things with the name of "nano" as high-class. But what is nanotechnology? What can it do and what will it bring us in the future?

Nanotechnology, a young but active field of science and technology, deals with objects at the nanometer level. The prefix "nano" means "one-billionth," so one nanometer is one-billionth of a meter. When working in such a tiny scale range, scientists and manufacturers measure things and activities by nanometers. They focus their study on the control and use of atoms or molecules in order to make amazingly small but highly effective materials, tools, and machines.

Today, laboratories and industries in different fields are creating more and more things "nano," from electronic products to cosmetics, clothing, and even food, although many such products are not truly "nano" in the strict sense of the word. Strictly "nano" or not, the trend is for products to become smaller, yet offer more and better functions. Here in Taiwan, the government has developed the NanoMark System, not only to encourage industries to make quality nanometerials and nanoproducts, but also to help people understand and accept them.

"Going nano" will certainly become an international trend in the twenty-first century. Nanotech scientists and engineers must continue to work hard to make nanotechnology dreams come true. It is likely that in the future, factories will turn out large quantities of powerful, wallet-size supercomputers at surprisingly low prices! The world is truly heading into an age of nanotechnology.

\begin{tabular}{|clll|}
\hline Vocabulary & & \\
\hline 1. & nanotechnology (n.) 奈米科技 & 9. & measure (v.) 測量、衡量 \\
2. & nanoproduct (n.) 奈米產品 & $10 . \quad$ molecule (n.) (分子) \\
3. & active (adj.) 活躍的 & 11. & electronic (adj.) 電子的 \\
4. & deal with (v.) 討論、處理 & $12 . \quad$ encourage (v.) 鼓勵 \\
5. & nanometer (n.) 奈米 & 13. & nanomaterial (n.) 奈米材料 \\
6. & nano (adj.) 奈米的 & $14 . \quad$ nanotech (adj. \& n.) \\
7. & function (n.) 功能 & 奈米科技的、奈米科技 \\
8. & one-billionth 十億分之一 & $15 . \quad$ turn out (v.) 生產 \\
& & $16 . \quad$ quantity (n.) 數量 \\
\hline
\end{tabular}

